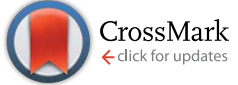

Cite this: RSC Adv., 2017, 7, 15272

\title{
Highly selective hydrodeoxygenation of anisole, phenol and guaiacol to benzene over nickel phosphide $\uparrow$
}

\begin{abstract}
Yunhua Li,* Juan Fu and Binghui Chen
$\mathrm{Ni}_{2} \mathrm{P}$ supported catalysts have extensively been studied for various hydrodeoxygenation (HDO) reactions. However, the main products are cyclohexane or cyclohexanol for lignin-derived compounds HDO over these catalysts. In this study, we investigate the catalytic conversion of anisole, phenol and guaiacol to benzene over $\mathrm{Ni}_{2} \mathrm{P} / \mathrm{SiO}_{2}$ by probing the reaction conditions. The results show that a lower reaction temperature and higher $\mathrm{H}_{2}$ pressure favour the hydrogenation of these model chemicals to cyclohexane, whereas a higher reaction temperature and lower $\mathrm{H}_{2}$ pressure aid the generation of benzene. The cyclohexane and benzene yields are $89.8 \%$ and $96.0 \%$ at $1.5 \mathrm{MPa}$ and $573 \mathrm{~K}$ and $0.5 \mathrm{MPa}$ and $673 \mathrm{~K}$, respectively. By eliminating the influence of internal and external diffusion, the low intrinsic activation energy of $58.2 \mathrm{~kJ} \mathrm{~mol}^{-1}$ is obtained, which explains the high catalytic activity. In addition, although guaiacol HDO has a low conversion due to the space steric effect of its substituents, it presents a similar reaction pathway to obtain anisole and phenol, which is dependent on reaction conditions. The long-run evaluation experiment shows that the activity and selectivity of anisole HDO to benzene changes slightly for $36 \mathrm{~h}$.
\end{abstract}

Received 23rd January 2017

DOI: $10.1039 / c 7 r a 00989 e$

rsc.li/rsc-advances their excellent HDO activity, their industrial application prospect is restricted due to their resource scarcity and high cost. In contrast, transition metal phosphide, ${ }^{18-22}$ nitride, ${ }^{23,24}$ carbide ${ }^{25,26}$ and $\mathrm{Ni}^{27-29}$ supported catalysts are relatively clean and efficient catalyst systems for the HDO process.

The key point of the hydrodeoxygenation reaction is the selective hydrogenation of certain groups in biomass-derived molecules. This involves two aspects in the HDO process of lignin model chemicals, such as guaiacol, phenol and anisole: selective hydrogenation of $\mathrm{C}_{\text {aromatic }}-\mathrm{O}$ and the benzene ring in oxygen-containing chemicals. Regarding their feasibility as vehicle fuel, higher occurrence of the former is vital because of their higher octane number together with the lower consumption of $\mathrm{H}_{2}$. To the best of our knowledge, the selective hydrogenation process is mainly dependent on the reasonable design of the components and structures of heterogeneous catalysts. ${ }^{30-34}$

Very recently, Zhao et al. pointed out that for the selective hydrogenolysis of lignin-derived substituted phenols, a higher temperature and lower $\mathrm{H}_{2}$ pressure contribute to the generation of benzene over the Ru/HZSM- 5 catalyst. ${ }^{35}$ In the previous study, we systematically studied phenol HDO over $\mathrm{Ni}_{2} \mathrm{P}$ and $\mathrm{Ni}_{2} \mathrm{P} @ \mathrm{Pd}$ supported catalysts using autoclave reactors. ${ }^{36,37}$ However, the main products are cyclohexane and cyclohexanol over these catalysts. Herein, the influence of the HDO reaction conditions on the reaction products is investigated over the base metal phosphide in a fixed bed. The reaction pathways of the highly selective HDO of phenol, anisole and guaiacol to benzene are 
uncovered by the reaction evaluation and physiochemical characterization of the $\mathrm{Ni}_{2} \mathrm{P}$ catalyst. Compared with the traditional studies, the present study has four advantages: (1) by simply changing the reaction conditions, benzene or cyclohexane is achieved, (2) the intrinsic activation energy is obtained through the elimination of internal and external diffusion to determine the high catalytic performance of the $\mathrm{Ni}_{2} \mathrm{P}$ catalyst fundamentally, (3) the reaction pathway is elucidated for the efficient conversion of lignin model compounds into benzene over $\mathrm{Ni}_{2} \mathrm{P}$ supported catalysts, and (4) the phosphide supported catalyst has high stability in the presence of a large amount of benzene.

\section{Experimental}

\section{Materials}

Guaiacol (GC grade) used for analysis was obtained from Aladdin Chemistry Co., Ltd. All other chemicals, such as benzene, phenol, and anisole, of analytical grade were purchased from Sinopharm Chemical Reagent Co., Ltd, and used as received without any further purification.

\section{Catalyst synthesis}

$\mathrm{Ni}_{2} \mathrm{P} / \mathrm{SiO}_{2}$ was prepared according to a similar method in ref. 36 . In a typical preparation, $2.62 \mathrm{~g} \mathrm{Ni}\left(\mathrm{NO}_{3}\right)_{2} \cdot 6 \mathrm{H}_{2} \mathrm{O}$ and $60 \mathrm{~g}$ urea were dissolved in $225 \mathrm{~mL}$ deionized water and stirred for $30 \mathrm{~min}$. The mixture was slowly added to a tetraethoxysilane (TEOS) precursor solution, which was obtained by dissolving $20.95 \mathrm{~g}$ TEOS in $20 \mathrm{~mL}$ ethanol. After stirring for $4 \mathrm{~h}$, drying for $12 \mathrm{~h}$ at $393 \mathrm{~K}$ and calcination for $4 \mathrm{~h}$ at $823 \mathrm{~K}$ in a muffle furnace, $\mathrm{NiO} / \mathrm{SiO}_{2}$ was obtained. Then, the as-obtained $\mathrm{NiO} / \mathrm{SiO}_{2}$ was impregnated with a certain amount $\mathrm{NH}_{4} \mathrm{H}_{2} \mathrm{PO}_{4}$ solution. After reducing for $3 \mathrm{~h}$ at $923 \mathrm{~K}$ in $\mathrm{H}_{2}$ atmosphere, $\mathrm{Ni}_{2} \mathrm{P} / \mathrm{SiO}_{2}$ was synthesized after passivation for $2 \mathrm{~h}$ in a flow of $0.5 \% \mathrm{O}_{2} / \mathrm{N}_{2}$ at room temperature.

\section{Materials characterization}

X-ray powder diffraction (XRD) measurement carried out on a PANalytical X'Pert Pro diffractometer with $\mathrm{Cu} \mathrm{K} \alpha$ radiation was used to elucidate the crystallographic properties of the sample. The $2 \theta$ scans covered the range of $10-90^{\circ}$ at a rate of $10^{\circ}$ $\min ^{-1}$. The crystallite size of the sample was estimated using the Scherrer equation. The particle sizes of the catalysts were characterized via transmission electron microscopy (TEM, FEI TECNAI F30). Before TEM observation, the $\mathrm{Ni}_{2} \mathrm{P}$ catalyst was sonicated in ethanol onto a holey-carbon coated copper grid and dried in air for $30 \mathrm{~min}$.

The BET (Brunauer-Emmett-Teller) surface area, pore volume and mesopore diameter distribution were measured via $\mathrm{N}_{2}$ adsorption-desorption measurements, which were carried out at $77 \mathrm{~K}$ using a Micromeritics ASAP 2020 system. Before the analyses, the samples were outgassed at $523 \mathrm{~K}$ for $2 \mathrm{~h}$.

The real Ni loading was tested by X-ray fluorescence (XRF, Bruker S8 TIGER) measurements. Carbon element analysis was carried out with an elemental analyzer (Vario ELIII, Elementar).

X-ray photoelectron spectroscopy (XPS) was conducted using a Quantum 2000 Scanning ESCA Microprobe system with focused monochromatic Al K $\alpha$ X-rays (1486.6 eV) under ultrahigh vacuum. Prior to the test, the sample was reduced in pure $\mathrm{H}_{2}\left(100 \mathrm{~mL} \min ^{-1}\right)$ at $723 \mathrm{~K}$ for $2 \mathrm{~h}$. Binding energies were calibrated using the $\mathrm{C}$ 1s peak at $284.8 \mathrm{eV}$ as a reference.

CO chemisorption was conducted on a Micromeritics ASAP 2020 equipped with a thermal conductivity detector (TCD). Prior to the test, $0.1 \mathrm{~g}$ passivated sample was treated at $723 \mathrm{~K}$ under an $\mathrm{H}_{2}$ stream $\left(40 \mathrm{~mL} \mathrm{~min}^{-1}\right)$ for $2 \mathrm{~h}$ and evacuated for $2 \mathrm{~h}$ at room temperature. The adsorbed $\mathrm{CO}$ was determined from the difference between the two isotherms.

\section{Evaluation of $\mathrm{HDO}$ on $\mathrm{Ni}_{2} \mathrm{P}$ catalysts}

All reactions were performed using a fixed-bed reactor (I.D. 8 $\mathrm{mm}$ ) with a thermocouple to monitor the reaction temperature. In a typical operation, $0.2 \mathrm{~g}$ catalyst was reduced in pure $\mathrm{H}_{2}$ (100 $\mathrm{mL} \min ^{-1}$ ) at $723 \mathrm{~K}$ for $1 \mathrm{~h}$ and cooled to a certain temperature. The reaction mixture with a ratio of $\mathrm{H}_{2}$ /oxygen-containing chemicals, anisole or guaiacol of 45 was introduced into the reactor. In the reaction process, the reaction products were detected online by gas chromatography connected with the fixed-bed.

\section{Results and discussion}

The structure and composition properties of $\mathrm{Ni}_{2} \mathrm{P} / \mathrm{SiO}_{2}$ were determined by physical characterizations. According to the TEM image shown in Fig. 1, the metal nanoparticles are uniformly distributed on the silica carrier (Fig. 1a-c) and the particle size is determined to be $5.35 \mathrm{~nm}$ based on 200 particles (Fig. 1d). This is in agreement with the value of $5.60 \mathrm{~nm}$ from the XRD (Fig. S1 $\dagger$ ) observations. In addition, the HR-TEM images taken of individual particles further present a $d$-spacing of $0.22 \mathrm{~nm}$, which is consistent with the (111) crystallographic plane of $\mathrm{Ni}_{2} \mathrm{P} .{ }^{38}$ Table $\mathrm{S} 1 \uparrow$ lists the composition and structure of the $\mathrm{Ni}_{2} \mathrm{P}$ supported catalyst. The actual load of $\mathrm{Ni}_{2} \mathrm{P}$ is $7.5 \%$ as

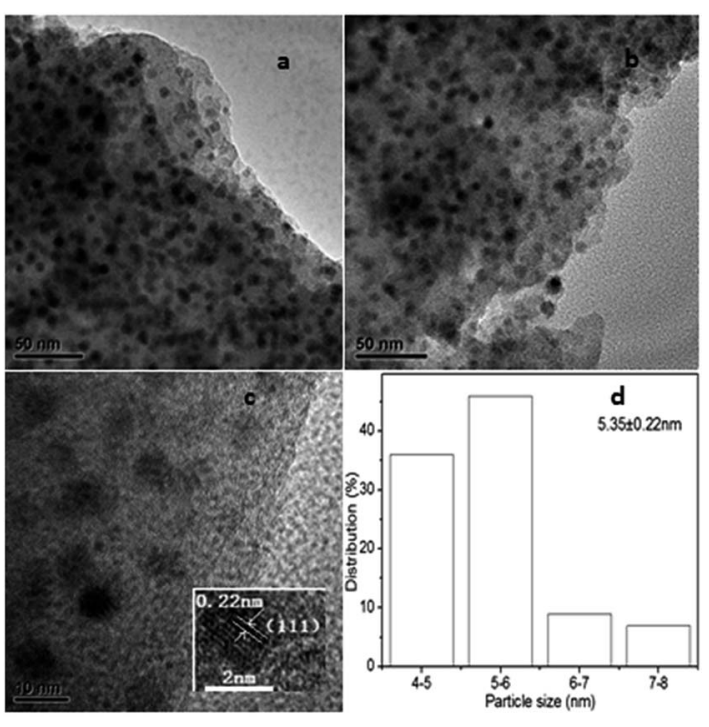

Fig. 1 TEM images and particle size distribution for the $\mathrm{Ni}_{2} \mathrm{P}$ catalyst. 

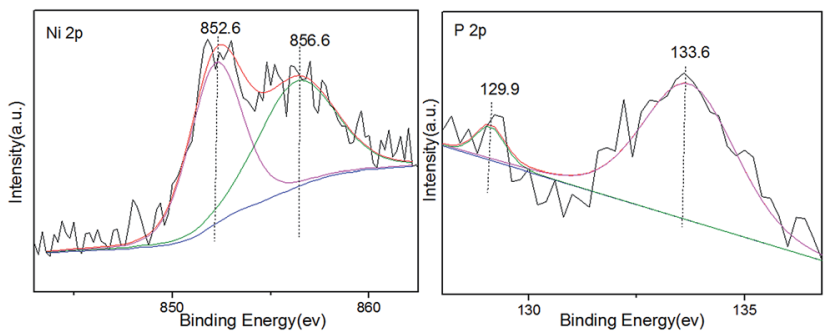

Fig. 2 XPS spectra of $\mathrm{Ni} 2 \mathrm{p}$ and $\mathrm{P} 2 \mathrm{p}$ of the $\mathrm{Ni}_{2} \mathrm{P} / \mathrm{SiO}_{2}$ catalyst.

determined by XRF and the surface area determined by BET is $316 \mathrm{~m}^{2} \mathrm{~g}^{-1}$. The amount of $\mathrm{CO}$ adsorbed on $\mathrm{Ni}_{2} \mathrm{P} / \mathrm{SiO}_{2}$ is 114 $\mu \mathrm{mol} \mathrm{CO}$ on per gram catalyst. The XPS spectra in Fig. 2 further show that $\mathrm{Ni}_{2} \mathrm{P} / \mathrm{SiO}_{2}$ includes $\mathrm{Ni}^{\delta+}(0<\delta<2)$ and $\mathrm{P}^{\delta-}(0<\delta<1)$ in $\mathrm{Ni}_{2} \mathrm{P}$ at about $852.6 \mathrm{eV}$ and $129.9 \mathrm{eV}$ (ref. 37) as well as $\mathrm{Ni}^{2+}$ and $\mathrm{P}^{5+}$ from the oxidation of $\mathrm{Ni}_{2} \mathrm{P}$ at about $856.6 \mathrm{eV}$ and $133.6 \mathrm{eV}$, respectively.

In order to make lignin model compounds efficiently convert into benzene by only changing the reaction conditions, the influence of reaction temperature was systematically investigated on the product distributions of anisole HDO.

As can be seen from Table 1, at $523 \mathrm{~K}$, anisole conversion is very low and the main products are cyclohexane and methoxylcyclohexane. When the temperature increases to $573 \mathrm{~K}$, cyclohexane further increases with a decrease in methoxylcyclohexane. In other words, the $\mathrm{C}_{\text {aromatic }}-\mathrm{O}$ bonds cleave and anisole is converted into cyclohexane with an increase in temperature, which indicates the occurrence of the reaction according to pathways I and II in Fig. 3. In contrast, the selectivity of benzene remains almost constant below $573 \mathrm{~K}$. As the temperature further increases up to $673 \mathrm{~K}$, the benzene selectivity prominently increases from $5.8 \%$ to $60.6 \%$, which indicates that a high temperature favors deoxygenation to generate a large amount of benzene for anisole HDO.

To distinctly understand the HDO reaction intrinsic process, we changed the space velocities and reduced the particle sizes to determine the influence of internal and external diffusion on the macroscopic rate of anisole HDO. When the liquid hourly space velocity exceeds $0.93 \mathrm{~h}^{-1}$ and the particle diameter is less than $0.25 \mathrm{~mm}$ at $673 \mathrm{~K}$ (Fig. S2 $\dagger$ ), the conversion of anisole remains constant. In other words, the catalytic results in Table 1 are obtained under the circumstance of negligible internal and

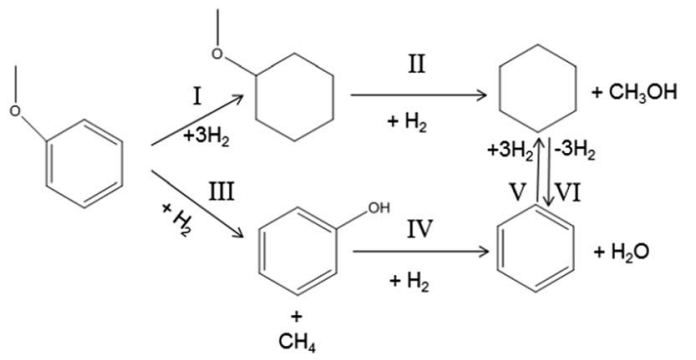

Fig. 3 Reaction pathway for anisole HDO.

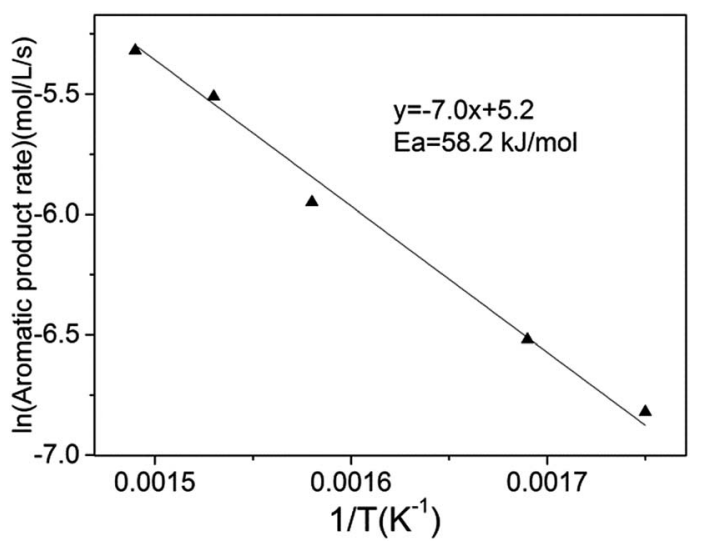

Fig. 4 Intrinsic activation energy for anisole $\mathrm{HDO}$ over the $\mathrm{Ni}_{2} \mathrm{P} / \mathrm{SiO}_{2}$ catalyst. Reaction conditions: 573-673 K, $1.5 \mathrm{MPa}$, LHSV $1.85 \mathrm{~h}^{-1}$, and particle diameter $0.18 \mathrm{~mm}$.

external diffusion. Furthermore, the intrinsic activation energy of anisole HDO is presented in Fig. 4, which is similar to the research of H. Y. Zhao. ${ }^{18}$ It is lower than expected for carbonoxygen bond rupture $\left(>240 \mathrm{~kJ} \mathrm{~mol}^{-1}\right)$, which reflects the high activity of the transition metal phosphide for anisole HDO.

The effects of $\mathrm{H}_{2}$ pressure on the product distribution in anisole HDO were also studied, and the results presented in Table 2. As demonstrated in Table 2, anisole is partially converted into cyclohexane and phenol under atmospheric pressure. With an increment in $\mathrm{H}_{2}$ pressure, anisole is consumed completely and the main products become benzene and cyclohexane. The higher the $\mathrm{H}_{2}$ pressure, the more cyclohexane is generated together with the less benzene. This result confirms

Table 1 Catalytic performances ${ }^{a}$ at different temperatures in anisole HDO

\begin{tabular}{|c|c|c|c|c|c|c|}
\hline & & $\operatorname{TOF}^{b}\left(\mathrm{~s}^{-1}\right)$ & \multicolumn{4}{|l|}{ Selectivity (\%) } \\
\hline 573 & 97.0 & 0.18 & 92.6 & 5.8 & 1.6 & 0 \\
\hline 623 & 97.5 & 0.19 & 88.0 & 12.0 & 0 & 0 \\
\hline 673 & 100 & 0.19 & 39.4 & 60.6 & 0 & 0 \\
\hline
\end{tabular}

${ }^{a}$ Reaction condition: $1.5 \mathrm{MPa}$, liquid hour space velocity (LHSV) $1.85 \mathrm{~h}^{-1}$, particle diameter $0.18 \mathrm{~mm}, \mathrm{H}_{2} /$ anisole mole ratio $45 .{ }^{b}$ The turnover frequency (TOF) was calculated based on linear-type CO chemisorption. 
Table 2 Catalytic performances ${ }^{a}$ under different pressures in anisole HDO

\begin{tabular}{|c|c|c|c|c|c|}
\hline \multirow[b]{2}{*}{ Pressure (MPa) } & \multirow[b]{2}{*}{ Conversion (\%) } & \multicolumn{4}{|c|}{ Selectivity (\%) } \\
\hline & & Cyclohexane & Benzene & Methoxyl cyclohexane & Phenol \\
\hline 0.1 & 70.8 & 0 & 54.6 & 0 & 45.4 \\
\hline 0.5 & 100 & 3.6 & 96.4 & 0 & 0 \\
\hline 1.5 & 100 & 39.4 & 60.6 & 0 & 0 \\
\hline 2.0 & 100 & 53.6 & 46.4 & 0 & 0 \\
\hline
\end{tabular}

${ }^{a}$ Reaction conditions: $673 \mathrm{~K}$, LHSV $1.85 \mathrm{~h}^{-1}$, particle diameter $0.18 \mathrm{~mm}$, and $\mathrm{H}_{2}$ /anisole mole ratio 45 .

the existence of reaction process $\mathrm{V}$ in Fig. 2. In addition, at $673 \mathrm{~K}$ and $0.5 \mathrm{MPa}$, cyclohexane as a reactant has $20.1 \%$ conversion to benzene. This is reduced to $10.0 \%$ at the same temperature and 1.5 MPa.

Based on these results, we speculate the reaction pathways for anisole HDO at different temperatures in Fig. 3. At about 573 $\mathrm{K}$ and 1.5 MPa the anisole HDO reaction occurs following the pathways I and II, whereas the HDO reaction mainly proceeds according to pathways III, IV, V and VI at $673 \mathrm{~K}$ and $0.5 \mathrm{MPa}$ (Table 2).

A mixture of anisole and phenol (mass ratio of anisole and phenol is equal to 1.0), and guaiacol were used as reactants to further investigate the HDO properties of the model chemicals from lignin pyrolysis oil, and the results are presented in Table 3. From Table 3, it can be seen that phenol has similar reaction features to anisole under the same reaction conditions. Specifically, at $573 \mathrm{~K}$, the benzene ring is easily hydrogenated, whereas at $673 \mathrm{~K}, \mathrm{C}_{\text {aromatic }}-\mathrm{O}$ preferentially cleaves to benzene over the $\mathrm{Ni}_{2} \mathrm{P}$ catalyst. In addition, the evaluation results from the HDO of guaiacol with methoxyl and phenolic hydroxyl groups (Table 3) show that the consumption of guaiacol follows a similar HDO pathway to anisole and phenol under the same reaction conditions despite the relatively lower conversion. Guaiacol HDO is inhibited in comparison with anisole and phenol, which may result from the steric hindrance effect of its functional groups ${ }^{39}$ in the reaction process. In addition, elemental analysis presents that $4.6 \%$ carbon is generated over $\mathrm{Ni}_{2} \mathrm{P} / \mathrm{SiO}_{2}$ after the guaiacol HDO reaction (Table $\mathrm{S} 2 \dagger$ ).

We also further checked the effect of LHSV on product distribution in anisole HDO (Table 4). In the range of LHSV from 0.93 to $7.4 \mathrm{~h}^{-1}$, the conversion of anisole initially remains almost constant and then decreases gradually, whereas the selectivity of products varies slightly. With the increase in LHSV from 0.9 to $1.8 \mathrm{~h}^{-1}$, the excellent catalytic activity of $\mathrm{Ni}_{2} \mathrm{P}$ results in the high conversion of anisole. However, some of the anisole is left in the reaction system as LHSV further increases. A high LHSV means a short reaction time, which does not contribute to all of the anisole contacting with the catalyst surface. Thus,

Table 3 Catalytic performances ${ }^{a}$ of the different model chemicals

\begin{tabular}{|c|c|c|c|c|c|c|}
\hline Reactant & $\begin{array}{l}\text { Temperature } \\
(\mathrm{K})\end{array}$ & Pressure (MPa) & Con. $^{b}(\%)$ & \multicolumn{3}{|l|}{ Selectivity (\%) } \\
\hline & 673 & 0.5 & 100 & 4.3 & 95.7 & 0.0 \\
\hline \multirow[t]{2}{*}{ Guaiacol } & 573 & 1.5 & 91.0 & 96.5 & 3.5 & 0 \\
\hline & 673 & 0.5 & 91.7 & 5.0 & 74.0 & 21.0 \\
\hline
\end{tabular}

${ }^{a}$ Reaction conditions: LHSV $1.85 \mathrm{~h}^{-1}$, particle diameter $0.18 \mathrm{~mm}$, and $\mathrm{H}_{2} /$ anisole (phenol or guaiacol) mole ratio $45 .{ }^{b}$ Conversions of anisole and phenol are equal to $100 \%$ for the HDO reaction of the mixture containing anisole and phenol. ${ }^{c}$ Phenol selectivity is for guaiacol HDO.

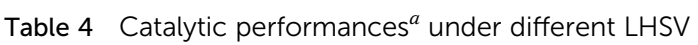

\begin{tabular}{|c|c|c|c|c|c|}
\hline $\operatorname{LHSV}\left(\mathrm{h}^{-1}\right)$ & Conversion (\%) & Cyclohexane & Benzene & Methoxyl cyclohexane & Phenol \\
\hline 1.8 & 100 & 3.6 & 96.4 & 0 & 0 \\
\hline 3.7 & 98.0 & 3.8 & 96.2 & 0 & 0 \\
\hline 7.4 & 95.6 & 2.6 & 97.4 & 0 & 0 \\
\hline
\end{tabular}

${ }^{a}$ Reaction conditions: $673 \mathrm{~K}, 0.5 \mathrm{MPa}$, particle diameter $0.18 \mathrm{~mm}$, and $\mathrm{H}_{2}$ /anisole mole ratio 45 . 

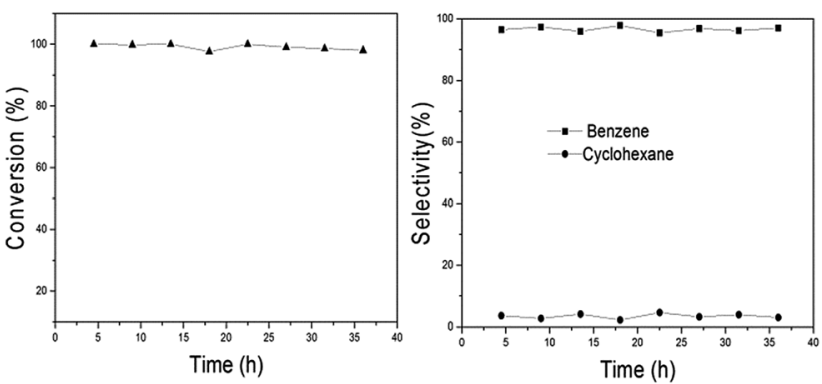

Fig. 5 Stability for anisole $\mathrm{HDO}$ over $\mathrm{Ni}_{2} \mathrm{P} / \mathrm{SiO}_{2}$. Reaction conditions: $673 \mathrm{~K}$, LHSV $1.85 \mathrm{~h}^{-1}$, particle diameter $0.18 \mathrm{~mm}$, and $\mathrm{H}_{2}$ /anisole mole ratio 45 .

anisole conversion initially remains constant and then drops slowly.

Since $\mathrm{Ni}_{2} \mathrm{P} / \mathrm{SiO}_{2}$ has high benzene selectivity for anisole HDO, the stability of the catalyst also becomes a significant issue in the presence of a large amount of benzene. Herein, anisole HDO was run for $36 \mathrm{~h}$ (Fig. 5) and then an element analysis was performed to determine the carbon content on the catalyst surface before and after the reaction (Table S2 $\dagger$ ). As shown Fig. 5 and Table S2, $\uparrow$ the conversion and selectivity within $36 \mathrm{~h}$ have no obvious decline and the formation of carbon cannot be observed after the reaction. These results show that the $\mathrm{Ni}_{2} \mathrm{P} / \mathrm{SiO}_{2}$ catalyst has relatively good stability for anisole HDO to benzene.

\section{Conclusions}

In this study, the HDO of anisole, guaiacol and phenol was investigated to obtain high benzene yield over $\mathrm{Ni}_{2} \mathrm{P} / \mathrm{SiO}_{2}$. The results show that with an increase in the reaction temperature from $573 \mathrm{~K}$ to $673 \mathrm{~K}$, the selectivity of benzene prominently increases from $5.8 \%$ to $60.6 \%$. In addition, the benzene yield reaches $96.0 \%$ from anisole or phenol HDO with a decrease in reaction pressure. In other words, a higher reaction temperature and lower $\mathrm{H}_{2}$ pressure favor the conversion of anisole to benzene. Conversely, hydrogenation of the benzene ring occurs. $58.2 \mathrm{~kJ} \mathrm{~mol}^{-1}$ of intrinsic activation energy at 573-673 K further accounts for the high catalytic activity of nickel phosphide. The long-run evaluation of anisole HDO to benzene shows that the catalytic performances change negligibly for $36 \mathrm{~h}$. Although guaiacol HDO shows a low conversion due to the space steric effect of its substituent, it has similar reaction characteristics to anisole and phenol conversion to benzene under the same conditions. This work demonstrates that the $\mathrm{Ni}_{2} \mathrm{P}$ supported catalyst is an efficient and promising catalyst for HDO in industrial application. At the same time, it also provides important information for the development of other catalysts for the conversion of lignin model chemicals to benzene.

\section{Acknowledgements}

This study was supported by National Natural Science Foundation of China (Grant no. 21476188, 21106118).

\section{Notes and references}

1 L. E. Manzer, Top. Catal., 2010, 53, 1193-1196.

2 X. Chen, B. Zhang, Y. Wang and N. Yan, Chimia, 2015, 69, 120-124.

3 S. De, B. Saha and R. Luque, Bioresour. Technol., 2015, 178, 108-118.

4 H. Liu, T. Chen, X. Zhang, J. Li, D. Chang and L. Song, Chin. J. Catal., 2010, 31, 409-414.

5 P. S. Rezaei, H. Shafaghat and W. M. A. W. Daud, Appl. Catal., A, 2014, 469, 490-511.

6 G. Liang, A. Wang, X. Zhao, N. Lei and T. Zhang, Green Chem., 2016, 18, 3430-3438.

7 D. Nguyen Thanh, O. Kikhtyanin, R. Ramos, M. Kothari, P. Ulbrich, T. Munshi and D. Kubička, Catal. Today, 2016, 277, 97-107.

8 K. C. Kwon, H. Mayfield, T. Marolla, B. Nichols and M. Mashburn, Renewable Energy, 2011, 36, 907-915.

9 M. Badawi, J. F. Paul, S. Cristol, E. Payen, Y. Romero, F. Richard, S. Brunet, D. Lambert, X. Portier, A. Popov, E. Kondratieva, J. M. Goupil, J. El Fallah, J. P. Gilson, L. Mariey, A. Travert and F. Maugé, J. Catal., 2011, 282, 155-164.

10 V. N. Bui, D. Laurenti, P. Afanasiev and C. Geantet, Appl. Catal., B, 2011, 101, 239-245.

11 M. C. Samolada, W. Baldauf and I. A. Vasalos, Fuel, 1998, 77, 1667-1675.

12 O. İ. Şenol, E. M. Ryymin, T. R. Viljava and A. O. I. Krause, J. Mol. Catal. A: Chem., 2007, 277, 107-112.

13 O. İ. Şenol, T. R. Viljava and A. O. I. Krause, Appl. Catal., A, 2007, 326, 236-244.

14 Y. Huang, L. Wei, X. Zhao, J. Julson, C. Qiu, S. Dharmarajan, J. Kiratu, D. Raynie, A. Dubey and Q. Qiao, Int. J. Energy Res., 2016, 40, 1724-1730.

15 M. S. Zanuttini, B. O. Dalla Costa, C. A. Querini and M. A. Peralta, Appl. Catal., A, 2014, 482, 352-361.

16 J. K. Hedlund, D. C. Cronauer, G. Jacobs, A. J. Kropf, J. A. Libera, J. W. Elam, C. L. Marshall, V. R. R. Pendyala and B. H. Davis, Catal. Lett., 2016, 146, 525-539.

17 C. A. Teles, R. C. Rabelo-Neto, J. R. de Lima, L. V. Mattos, D. E. Resasco and F. B. Noronha, Catal. Lett., 2016, 146, 1848-1857.

18 H. Y. Zhao, D. Li, P. Bui and S. T. Oyama, Appl. Catal., A, 2011, 391, 305-310.

19 K. Li, R. Wang and J. Chen, Energy Fuels, 2011, 25, 854-863. 20 Y. Shu, Y. Lee and S. Oyama, J. Catal., 2005, 236, 112-121.

21 D. J. Rensel, S. Rouvimov, M. E. Gin and J. C. Hicks, J. Catal., 2013, 305, 256-263.

22 W. Fu, L. Zhang, D. Wu, Q. Yu, T. Tang and T. Tang, Ind. Eng. Chem. Res., 2016, 55, 7085-7095.

23 B. M. Wyvratt, J. R. Gaudet, D. B. Pardue, A. Marton, S. Rudić, E. A. Mader, T. R. Cundari, J. M. Mayer and L. T. Thompson, ACS Catal., 2016, 6(9), 5797-5806.

24 S. Verma, R. B. N. Baig, M. N. Nadagouda and R. S. Varma, Green Chem., 2016, 18, 1327-1331. 
25 A. L. Jongerius, R. W. Gosselink, J. Dijkstra, J. H. Bitter, P. C. A. Bruijnincx and B. M. Weckhuysen, ChemCatChem, 2013, 5, 2964-2972.

26 W.-S. Lee, Z. Wang, R. J. Wu and A. Bhan, J. Catal., 2014, 319, 44-53.

27 S. Jin, Z. Xiao, C. Li, X. Chen, L. Wang, J. Xing, W. Li and C. Liang, Catal. Today, 2014, 234, 125-132.

28 S. Qi, W. Feng and X. Jie, Chem. Commun., 2012, 48, 70197021.

29 Q. Song, F. Wang, J. Cai, Y. Wang, J. Zhang, W. Yu and J. Xu, Energy Environ. Sci., 2013, 6, 994-1007.

30 S. T. Oyama, T. Onkawa, A. Takagaki, R. Kikuchi, S. Hosokai, Y. Suzuki and K. K. Bando, Top. Catal., 2015, 58, 201-210. 31 P. Bui, J. Catal., 2012, 294, 184-198.

32 K. Wu, W. Wang, S. Tan, G. Zhu, L. Tan and Y. Yang, RSC Adv., 2016, 6, 80641-80648.
33 S. K. Wu, P. C. Lai, Y. C. Lin, H. P. Wan, H. T. Lee and Y. H. Chang, ACS Sustainable Chem. Eng., 2013, 1, 349-358. 34 S. K. Wu, P. C. Lai and Y. C. Lin, Catal. Lett., 2014, 144, 878889.

35 Z. Luo, Z. Zheng, Y. Wang, G. Sun, H. Jiang and C. Zhao, Green Chem., 2016, 18, 5845-5858.

36 Y. Li, X. Yang, L. Zhu, H. Zhang and B. Chen, RSC Adv., 2015, 5, 80388-80396.

37 K. Yan, Y. Li, X. Zhang, X. Yang, N. Zhang, J. Zheng, B. Chen and K. J. Smith, Int. J. Hydrogen Energy, 2015, 40, 1613716146.

38 S. Wang, K. Wang and X. Wang, Appl. Surf. Sci., 2016, 386, 442-450.

39 S. F. Guo, A. K. Rogers, M. M. Yung and C. Sievers, ACS Catal., 2016, 1292-1307. 